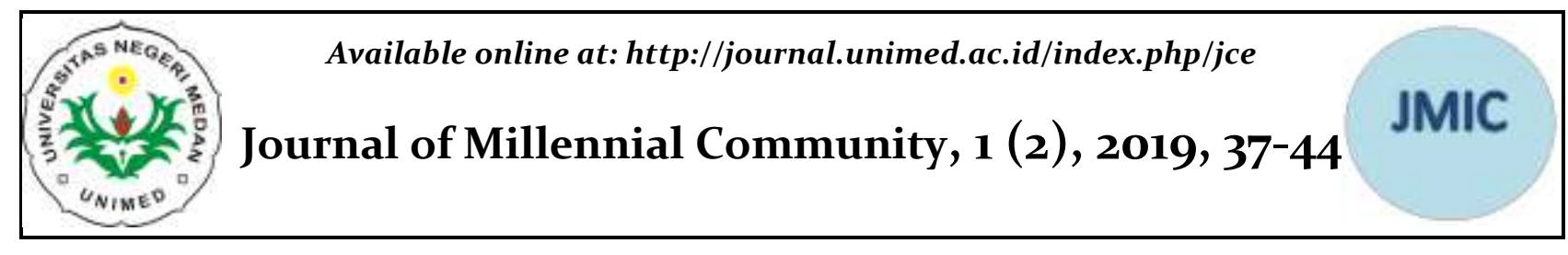

\title{
Pemuda Sebagai Fasilitator Pendamping Desa
}

\author{
Syamsuddin, M.Pd \\ Universitas Nahdlatul Ulama Kalimantan Timur \\ Email: syamsuddin@unukaltim.ac.id Telp: +6281352696565
}

\begin{abstract}
Abstrak
Pendampingan Desa adalah kegiatan untuk melakukan tindakan pemberdayaan masyarakat melalui asistensi, pengorganisasian, pengarahan dan fasilitasi Desa. Setiap desa memiliki keragaman potensi berbeda. Potensi Desa mampu di aktualisasikan sesuai dengan perancanaan dan tata kelola desa yang mapan demi keberlanjutan pembangunan desa (sustainable development). Keberlanjutan ditandai dengan adanya Generasi (pemuda) yang lahir dari realitas sosial dan sistem pengetahuan adat istiadat yang memiliki modal sosial (social capital) untuk berinteraksi dan berpartisipatif dalam self governing community sebagai fasilitator pendamping desa. Dalam makalah ini, penulis menelaah pemuda sebagai fasilitator pendamping desa agar seluruh elemen terakait mampu menerjemahkan potensi pemuda sebagai empowerment dan bertujuan sebagai perwujudan pemuda dalam berpartisipasi untuk desa, bangsa dan negara.
\end{abstract}

Kata Kunci: pendamping desa, potensi, sustainable development, pemuda, modal soisal, self governing community, sustainable community facilitator.

\section{The Youth as A Village Facilitator}

\begin{abstract}
Village Facilitation is an activity to carry out community empowerment actions through assistance, organization, direction, and facilitation of the Village. Each village has a different potential diversity. Village Potential can be actualized by village planning and governance that are well established for the sake of sustainable village development (sustainable development). Sustainability is marked by the existence of Generations (youth) born from social reality and customary knowledge systems that have the social capital to interact and participate in the self-governing community as facilitators of village assistance. In this paper, the author examines youth as facilitators of village assistance so that all related elements can translate youth's potential as empowerment and aim as an embodiment of youth in participating for the village, nation, and state.
\end{abstract}

Keywords: village companion, potential, sustainable development, youth, social capital, selfgoverning community, sustainable community facilitator.

\section{PENDAHULUAN}

Manusia memiliki hal yang evident dalam dirinya, yakni fitrah dengan ragam potensi dan aktualnya. Seperti halnya manusia, begitu juga dengan Desa (UndangUndang Tentang Desa, 2014). Di Indonesia, desa berjumlah \pm 74.754 di tahun 2015 (Peraturan Menteri Dalam Negeri Tentang Kependudukan, 2015) yang memiliki keragaman dan kompleksitas potensi yang akan aktual mengikuti nalar perubahan dunia.

Potensi desa bukan saja terletak pada aspek-aspek material yang melimpah seperti Sumber Daya Alam (SDA) yang bisa diproduksi menjadi industri manufaktur (hulu) ataupun industri kecil dan menengah 
(hilir) yang mampu menciptakan ragam lapangan pekerjaan bagi masyarakat desa.

Keberadaan potensi yang telah aktual tentu mengalami fase degradasi (penyusutan). Sebuah pembaharuan SDA membutuhkan waktu bertahun-tahun agar bisa terbarukan. Perangkat desa yang teralatih, terdidik, terpercaya dalam mengelola potensi desa diharapkan mampu memanagement sumber daya desa. Sudah sepatunya pemerintah tidak lagi berharap pada SDA terbaurkan dan tak terbarukan, namun fokus pada kekuatan (empowerment) Sumber Daya Manusia (BJ Habibi, Presiden ke-3 RI).

Pemanfaatan potensi di aspek Sumber Daya Manusia (SDM). Maksudnya, setiap desa memiliki regenerasi potensial untuk mengembangkan dan memajukan desa, bukan saja bergerak dalam memobilisasi massa pada praksis-prasis sosial (sosial change), regenerasi tersebut bisa menjadi seorang leader yang mapan. Leader yang mapan adalah mereka yang memiliki keterampilan komunikasi yang apik, disiplin yang baik. Potensi yang ada pada SDM, harus jeli dilihat oleh perangkat desa untuk menjaga sustainable (keberlanjutan) kaderisasi dengan memperhalus skills, memberikan peltihan dan mendidiknya (Undang-undang Tentang Kepemudaan, 2009).

SDM dapat di sematkan pada terminologi pemuda. Pemuda yang lahir dari rahim desanya, yang sejak kecil ia tumbuh dari realitas sosial, kultur dan adat istiadat. Jika berkaca pada beberapa program skala nasional seperti program kesehatan dan pendidikan sering tidak efektif di kalangan masyarakat desa, karena kerap terjadi ketidak mampuan beradaptasi dengan baik terhadap masyarakat desa. Salah satu yang menjadi ciri self governing community adalah adanya hukum adat yang mengatur masalah pemerintahan, pengelolaan sumber daya alam, hubungan sosial yang pada prinsipnya untuk menjaga kesemibangan dan keberlanjutan hubungan antara manusia, tuhan dan alam (Nurcholis, 2011).

Maka penting sekiranya pemuda yang lahir dari realitas sosial desa urun angan untuk ikut berpatisipatif dalam menjaga dan mengawal keberlangusngan pembangunan dan peneyelenggaraan desa. Karena pemuda tersebut memahami psikologis sosial desa untuk merajut komunikasi-komunikasi yang missing understanding dalam sistem pengetahuan masayarakat desa.

Namun, permasalahan yang sering mengemuka pada pemuda, sering dipicu oleh beberapa hal; Pertama, ketidak percayaan tetua (orang tua) atau dalam hal ini perangkat desa kepada pemuda yang diklaim minim pengalaman (hard \& soft skill). Kedua, realitas pemuda yang telah menempu studi, pergi merantau kekota mencari pekerjaan sesuai passionnya. Ketiga, personalitas pemuda yang masih dalam kecendrungan hedon. Kempat, sangsi sosial ketika pemuda lulus studi haya tinggal dan kerja didesa, yang menyebabkan pemuda memilih meninggalkan desa.

Dengan adanya undang-undang no.6 tahun 2014 tentang desa, perangkat desa diharapkan inklusif dan memberi kesempatan kepada pemuda sebagai Kader Muda Desa (KEMUDI) untuk ikut berpartisipatif bersama-sama mendampingi self govering community, sebagai pengontrol dan pendamping untuk mejaga keberlangsungan pembangunan desa.

\section{PEMBAHASAN}

\section{Pemuda dan Kepemudaan}

Pemuda dan Kepemudaan dua terminologi yang secara artifisial terlihat sama. Namun dalam berbagai tinjauan keilmuan, dua kata tersebut memiliki arti dan makna yang dinamis. Dalam tinjauan ilmu biologi, pemuda dapat dartikan dan di identifikasi sebagai satu proses perubahan fisik (material) dari fase kanak-kanak ke fase remaja-dewasa.

Berbeda dengan perspektif biologis, pemuda juga bisa ditinjau dari aspek demografi. Dari jumlah penduduk yang di kategorikan sesuai rance usia. (lihat tabel dibawah). 
Tabel 1.1

Jumlah dan Presentase Penduduk Menurut Kelompok Umur dan Tipe Daerah, 2014

\begin{tabular}{|c|c|c|c|c|c|c|}
\hline \multirow{2}{*}{$\begin{array}{c}\text { Kelonopok Umur } \\
\text { (Tahus) }\end{array}$} & \multicolumn{2}{|c|}{ Perkothas (K) } & \multicolumn{2}{|c|}{ Perdesaan (D) } & \multicolumn{2}{|l|}{$\mathbf{K} \cdot \mathbf{D}$} \\
\hline & mabis $(000)$ & Persen & Tualah $\{000)$ & Perses & Juedat [000] & Persen \\
\hline (3) & (2) & (3) & (4) & (5) & (6) & $(7)$ \\
\hline$<10$ & 36860.72 & 29.18 & 19816.74 & 32.68 & 76677.46 & 30,42 \\
\hline $16-30$ & 3273157 & 25,92 & 29083.12 & 23,14 & 61834,60 & 24.53 \\
\hline$>30$ & 56720.89 & 44.90 & 5680201 & 45.19 & 113523.50 & 45.04 \\
\hline Jumlah & 126353,19 & 500.00 & $125702+6$ & 100.00 & 252035,65 & 100.00 \\
\hline
\end{tabular}

Sumber:BPS, Susenas Kor 2014

Tabel 1.2

Presentase Jumlah Pemuda Indonesia, 2010-2014

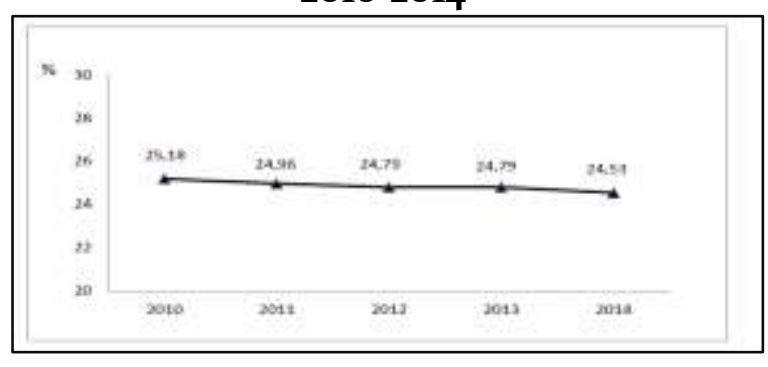

Sumber:BPS, Susenas Kor 2010- 2014

Dari kedua tabel diatas kita bisa melihat jumlah perentase pemuda yang berkembang secara dinamis dari tahun ke tahun. Pada tabel 1.1 menunjukkan jumlah pemuda Indonesia dengan rance usia 16-30 tahun berjumlah sekitar 61,83 juta jiwa atau $24,53 \%$ dari jumlah penduduk Indonesia yakni 252,035,065 juta jiwa (Undang-undang Tentang Kepemudaan, 2009).

Pada tabel 1.2 menunjukkan di tahun 2010 persentase pemuda Indonesia tercatat sebesar 25,18\%. Angka tersebut menurun menjadi 24,96 persen di tahun 2011. Pada tahun 2012 dan 2013 persentase pemuda mengalami penurunan menjadi sebesar 24,79 \% dan pada tahun 2014 menjadi sebesar $24,53 \%$.

Bila kita membandingakan tingkat presentase jumlah pemuda Indonesia pada tahun 1961 sampai dengan 1971 dengan rance usia muda di patok dari umur 10-24 tahun. Tahun 1961 berjumlah sekitar 23678,6 atau 24,6\% dan tahun 1971 berjumlah 33580,6 atau $28,4 \%$. Artinya, selama dasarwasa peningkatan jumlah pemuda saat itu meningkat $42 \%$.

Berbeda dengan persentase jumlah pemuda di Indonesia pada tahun 2010 hingga tahun 2014 cenderung mengalami penurunan. Penurunan tersebut bisa dilihat dari berbagai aspek, salah satunya ketika berhasilnya program Keluarga Berencana (KB) seperti yang di utarakan oleh (Abdullah, 1974). Penurunan presentase jumlah penduduk di tahun 2010 hingga 2014, pernah terjadi pada tahun 1971 hingga 2001, selanjut lihat tabel 1.3 berikut;

Tabel. 1.3

Proyeksi Pemuda di Indonesia 1971-20o1

\begin{tabular}{|lll|}
\hline Tahun & $\begin{array}{l}\text { Tanpa } \\
\text { Keluarga } \\
\text { Berencana } \\
(\text { KB })\end{array}$ & $\begin{array}{l}\text { Dengan } \\
\text { Keluarga } \\
\text { Berencaa }\end{array}$ \\
\hline 1971 & 35302 & 35302 \\
1976 & 42518 & 42518 \\
1981 & 50242 & 50242 \\
1986 & 56401 & 56401 \\
1991 & 63357 & 60979 \\
1996 & 72920 & 64459 \\
2001 & 86183 & 68381 \\
\hline
\end{tabular}

Sumber: Lembaga Demografi FEUI

Dengan jumlah presentase demografi pemuda di Indonesia tahun 2014, bahwa jumlah usia produktif di masa bonus demografi 2025-2040 memberi sinyal kepada negera Indonesia (seluruh elemen terkait) untuk menyambut dan mempersiapkan selurh asepek material ataupun nonmaterial agar dapat mengaktualkan potensi Generasi Emas sebagai sumber daya manusia yang produktif, aktif dan partisipatif dalam membangun dan menjaga kestabilan negara. Sumber daya manusia itu disebut Pemuda.

Fakta sejarah dari peran pemuda cukup memberikan ruang perubahan untuk negara Indonesia, salah satu dari sekian fakta sejarah adalah berdirinya organisasi modern Budi Utomo pada 1908 (Budi Utomo, 2005) kemudian pada Kongres Pemuda I di tahun 1926 dan Kongres Pemuda II di tahun 1928 (R.Z. Leirissa dkk, 1989) yang di tengarai oleh Sumpah Pemuda. 


\section{Journal of Millennial Community, 1 (2), September 2019}

Syamsuddin

Pemuda merupakan unsur yang menarik dan esensial dalam suatu gerakan perubahan, karena di dalam jiwa pemuda terdapat kerelaan berkorban demi cita-cita. Jika pemuda adalah aspek lahiriah maka kepemudaan adalah batiniah (jiwa) yang memiliki cita rasa perubahan dan secara potensial dimiliki oleh keseluruhan manusia (pemuda).

Dengan begitu sekiranya penting pemuda sebagai harapan masa depan bangsa Indoneisa harus dibina agar potensi roh/jiwa kepemudaanya sebagai pembeharu (social change) dapat teraktual untuk membangun negara, bangsa, daerah dan desa tempat ia tumbuh besar.

\section{Pemuda, Komunikasi dan Self Governing Community}

Pemuda yang lahir dari rahim realitas sosial (desa), budaya, adat istiadat dan sitem pengetahuan memiliki probabilitas untuk menjadi kader/regenerasi desa. Dalam hal ini kader desa merupakan seorang agent yang memiliki kapasitas dan kualitas diri yang mempuni diberbagai aspek, seperti komunikasi, life skill's dan leadership sebagai modal sosial.

Modalitas sosial tersebut merupakan nilai dimiliki individu yang di dapatkan dari hasil proses atau peremajaan. Setiap individu memiliki bakatnya masing-masing, hanya saja bakat tersebut bisa menjadi endapan di dalam diri bila tidak di asah melalui training dan pendidikan formal-nonfomal. Bakat sebagai modalitas memiliki nilai guna yang efektif dalam berkehidupan sosial. Dengan bakat gaya komunikasi yang kontekstual, pemuda diharapkan mampu bercakap sesuai dengan norma dan etika yang berlaku pada komunitas. Kemudian, dengan skill (kemampuan) tata kelola administratif dan ketajaman analisis dapat berguna untuk kemajuan lembaga (perangkat desa) dan masyarakat desa.

Masyarakat desa atau self governing community, pada umumnya mempunyai pemerintahan sendiri yang dikelola secara otonom tanpa ikatan hirarkis struktural dengan struktural yang lebih tinggi, dan memiliki ciri adanya hukum adat yang mengatur masalah pemerintahan, pengelolaan sumber daya, hubungan sosial, dan seterusnya (Nurcholis, 2011). Sedangkan, Undang-undang RI No.6 tahun 2014 tantang Desa dalam BAB I Pasal 1, desa adalah desa dan desa adat atau yang disebut dengan nama lain, selanjutnya disebut Desa, adalah kesatuan masyarakat hukum yang memiliki batas wilayah yang berwenang untuk mengatur dan mengurus urusan pemerintahan, kepentingan masyarakat setempat berdasarkan prakarsa masyarakat, hak asal usul, dan/atau hak tradisional yang diakui dan dihormati dalam sistem pemerintahan Negara Kesatuan Republik Indonesia.

Self governing community yang pada mulanya tidak mengenal sitem hirarki yang lebih tinggi di atasnya, kini secara inheran dan integral dengan sistem pemerintahan dengan catatan menghormati hak tradisonal yang berlaku. Walaupun dengan adanya transformasi tersebut diharapakan tidak ada missing dalam mengkomunikasikan dan menjalankan pembangunan desa.

Acap kali di temukan sebuah kekeliruan oleh seorang pendamping desa atau pekerja sosial di tahap komunikasi baik persuasif maupun ditahap sosialisasi. Para ahli pendamping desa tidak diragukan lagi bahawa mereka memiliki kualitas pengetahuan. Namun pengetahuan tersebut terkadang mendevaluasi pengetahuan masyarakat lokal, karna merasa memiliki pengatahuan lebih dari pada masyarakat sehingga ia bertindak tanpa melibatkan masayarakat setempat, yang pada akhirnya miss komunikasi antara masyarakat dan pendamping desa.

Menurut (Ife.J dan Frank T, 2015) menghargai pengetahuan lokal adalah sebuah komponen esensial dari setiap kerja pengembangan masyarakat. Masyarakat lokallah yang memiliki pengetahuan, kearifan dan keahlian ini, dan peran pekerja masyarakat adalah untuk mendengar dan belajar dari masyarakat, bukan mengajari masyarakat tentang problem dan kebutuhan mereka (Holand,J. \& Black burn, 1998).

Dalam pengertian yang dikemukakan oleh beberapa ahli diatas tentang pengembang masyarakat, secara ekstensif 
pengertian tersebut dalam makalah ini untuk menerangkan posisi seorang pendamping desa. Pedamping desa sebagai komunikator atau perpanjangan tangan dalam memberingan pengetahuan kepada masyarakat dituntut dalam pelaksanaanya tidak ada terjadinya noise (hambatan) dalam proses komunikasi.

Berbagai macam media komunikasi yang bisa di gunakan dan di lakukan oleh pendamping desa dalam menyampaikan maksud pesannya kepada masyarakat. Media yang digunakan seyogyanya mampu diterima dengan baik oleh masyarakat setempat, salah satu dari media tersebut adalah media seni. Media seni yang tumbuh dan berkembang di tengah-tengah masyarakat dan berakar pada kebudayaan lokal, antara lain bahasa, adat istiadat, nilainilai yang tercermin dan sebagainya (Kartodrjdo, 1984).

Penelitian tentang jenis pertunjukan rakyat tradisional yang tepat untuk keperluan menyampaikan pesan-pesan pembangunan pernah dilakukan dalam penelitian di Daerah Istimewa Yogyakarta dan Jawa Timur pada tahun 1967/1977 dan daerah Sumatrat Bara dan Riau pada tahun 197/1978. Dari sekian hasil penelitian pertunjukan rakyat terebut di antaranya; pertunjukan wayang, ludruk, Dul Muluk, Senjang, sandiwar sunda, dan lain-lain.

Dengan Demikian dalam proses komunikasi terhadap self govening community diharapkan sosok pemuda (kader desa) mendapatkan tempat untuk dapat mengkomunikasikan serta menjalakan pembangunan desa dengan menghormati hak-hak tradisional yang menjadi tatanan dan tuntunan masyarkat desa (self governing community).

\section{Partisipasi Pemuda sebagai Fasilitator Pendamping Desa}

Theodorson (Mardikanto, 1994), partisipasi merupakan keikutsertaan atau keterlibatan seseorang (individu atau warga masyarakat) dalam suatu kegiatan tertentu. Partisipasi adalah keterlibatan yang berkaitan dengan keadaan eksternal (Sastropoetro, 1986). Secara holistik defenisi partisipasi adalah keikutsertaan atau terut andilnya individu atau warga masyarakat yang memiliki tanggung jawab dalam proses perencanaan, pelaksanaan, dan pemantauan kebijakan yang langsung mempengaruhi kehidupan mereka.

Individu yang turut andil dan memegang tanggung jawab tersebut dapat di sematkan pada pemuda sebagai sumber daya manusia yang jiwa kepemudaannya aktif, potensial, tanggung jawab, hak, karakter, kapasitas, aktualisasi diri, dan cita-cita pemuda (Undang-undang Tentang Kepemudaan, 2009). Itu sebabnya pemuda mendapat gelar identitas sebagi pembaharu (agent of change). Maka sepatutnya pemuda dapat berekspresi dan meningkatkan kapasitas, tentu bukan hanya tanggung jawab pemuda, tetapi tanggung jawab seluruh elemen terkait (keluarga, stakeholders, lingkungan belajar) yang integratif dan interkoneksi sesuai amanah konstitusi (pasal 9). Keseriusan negara dalam merawat kepemudaan sebagai tonggak regenerasi bangsa, diterjemahkan dari landasan filosofis Pancasila dan UUD 45, kemudian termaktub dalam berbagai peraturan dan perundan-undang.

Bentuk partisipasi pemuda dapat di tempuh dengan bebagai cara, dalam makalah ini memfokuskan partisipasi pemuda sebagai fasilitator pendamping desa. Fasilitator adalah seseorang yang terlibat dalam kegiatan fasilitasi. Mereka membantu sekelompok orang memahami tujuan umum mereka dan membantu mereka untuk merencanakan bagaimana untuk mencapai tujuan, dalam melakukannya (Bens, 2012). Untuk tujuan dan peran sebagai fasilitator pendaping desa dapat dilihat Tabel $2.1 \mathrm{di}$ bawah ini. 
Journal of Millennial Community, 1 (2), September 2019

Syamsuddin

Tabel 2.1

Peraturan Pemerintah Desa No. 3 Th 2015 Tentang Pendampingan Desa

\begin{tabular}{|c|c|}
\hline \multicolumn{2}{|r|}{ Peraturan Pemerintah Desa No. 3 Tahun 2015 Tentang Pendampingan Desa } \\
\hline $\begin{array}{l}\text { Bab 1, } \\
\text { Pasal 1 } \\
(14)\end{array}$ & $\begin{array}{l}\text { Pendampingan Desa adalah kegiatan untuk melakukan tindakan pemberdayaan } \\
\text { masyarakat melalui asistensi, pengorganisasian, pengarahan dan fasilitasi Desa. }\end{array}$ \\
\hline Pasal 2 & $\begin{array}{l}\text { Tujuan pendampingan Desa dalam Peraturan Menteri ini meliputi: } \\
\text { a. Meningkatkan kapasitas, efektivitas dan akuntabilitas pemerintahan desa } \\
\text { dan pembangunan Desa; } \\
\text { b. Meningkatkan prakarsa, kesadaran dan partisipasi masyarakat Desa } \\
\text { dalam pembangunan desa yang partisipatif; } \\
\text { c. Meningkatkan sinergi program pembangunan Desa antar sektor; dan } \\
\text { d. Mengoptimalkan aset lokal Desa secara emansipatoris. }\end{array}$ \\
\hline Pasal 3 & $\begin{array}{l}\text { Ruang lingkup pendampingan Desa meliputi: } \\
\text { a. Pendampingan masyarakat Desa dilaksanakan secara berjenjang untuk } \\
\text { memberdayakan dan memperkuat Desa; } \\
\text { b. Pendampingan masyarakat Desa sesuai dengan kebutuhan yang } \\
\text { didasarkan pada kondisi geografis wilayah, nilai APB Desa, dan cakupan } \\
\text { kegiatan yang didampingi; dan } \\
\text { c. Pemerintah, pemerintah daerah provinsi, pemerintah daerah } \\
\text { kabupaten/kota, dan Pemerintah Desa melakukan upaya pemberdayaan } \\
\text { masyarakat Desa melalui pendampingan masyarakat Desa yang } \\
\text { berkelanjutan, termasuk dalam hal penyediaan sumber daya manusia dan } \\
\text { manajemen. }\end{array}$ \\
\hline Pasal 4 & $\begin{array}{l}\text { Pendampingan Desa dilaksanakan oleh pendamping yang terdiri atas: } \\
\text { a. tenaga pendamping profesional; } \\
\text { b. Kader Pemberdayaan Masyarakat Desa; dan/atau } \\
\text { c. pihak ketiga. }\end{array}$ \\
\hline Pasal 9 & $\begin{array}{l}\text { Kader Pemberdayaan Masyarakat Desa sebagaimana dimaksud dalam Pasal } 4 \\
\text { huruf (b) berkedudukan di Desa. }\end{array}$ \\
\hline & $\begin{array}{l}\text { Pendamping Desa melaksanakan tugas mendampingi Desa, meliputi: } \\
\text { a. mendampingi Desa dalam perencanaan, pelaksanaan, dan pemantauan } \\
\text { terhadap pembangunan Desa dan pemberdayaan masyarakat Desa; } \\
\text { b. mendampingi Desa dalam melaksanakan pengelolaan pelayanan sosial } \\
\text { dasar, pengembangan usaha ekonomi Desa, pendayagunaan sumber daya } \\
\text { alam dan teknologi tepat guna, pembangunan sarana prasarana Desa, dan } \\
\text { pemberdayaan masyarakat Desa; } \\
\text { c. melakukan peningkatan kapasitas bagi Pemerintahan Desa, lembaga } \\
\text { kemasyarakatan Desa dalam hal pembangunan dan pemberdayaan } \\
\text { masyarakat Desa; } \\
\text { d. melakukan pengorganisasian di dalam kelompok-kelompok masyarakat } \\
\text { Desa; } \\
\text { e. melakukan peningkatan kapasitas bagi Kader Pemberdayaan Masyarakat } \\
\text { Desa dan mendorong terciptanya kader-kader pembangunan Desa yang } \\
\text { baru; } \\
\text { f. mendampingi Desa dalam pembangunan kawasan perdesaan secara }\end{array}$ \\
\hline
\end{tabular}




\begin{tabular}{|c|c|}
\hline & $\begin{array}{l}\text { partisipatif; dan } \\
\text { g. melakukan koordinasi pendampingan di tingkat kecamatan dan } \\
\text { memfasilitasi laporan pelaksanaan pendampingan oleh Camat kepada } \\
\text { Pemerintah Daerah Kabupaten/Kota. }\end{array}$ \\
\hline Pasal 18 & $\begin{array}{l}\text { (1) Kader Pemberdayaan Masyarakat Desa bertugas untuk menumbuhkan dan } \\
\text { mengembangkan, serta menggerakkan prakarsa, partisipasi, dan swadaya gotong } \\
\text { royong. } \\
\text { (2) Dalam hal tugas sebagaimana dimaksud pada ayat (1), Kader Pemberdayaan } \\
\text { Masyarakat Desa melibatkan unsur masyarakat, yang meliputi: } \\
\text { a. kelompok tani; } \\
\text { b. kelompok nelayan; } \\
\text { c. kelompok pengrajin; } \\
\text { d. kelompok perempuan; } \\
\text { e. kelompok pemerhati dan perlindungan anak; } \\
\text { f. kelompok masyarakat miskin; dan } \\
\text { g. kelompok-kelompok masyarakat lain sesuai dengan kondisi sosial budaya } \\
\text { masyarakat Desa. }\end{array}$ \\
\hline
\end{tabular}

\section{SIMPULAN}

Makalah ini telah mengkaji dan memaparkan terkait masalah yang sering mengemuka pada pemuda (telah disebutkan dalam pendahuluan) melahirkan beberapa butir kesimpulan, diataranya; (1) seluruh elemen terkait baik persenoal, keluarga, stakeholders dan lingkuangan belajar mesti jeli melihat potensi pemuda; (2) memberikan ruang dengan menfasilitasi potensi tersebut agar dapat aktual dan bermanfaat bagi desa, bangsa dan Negara; (3) mengajarkan Nilanilai Pancasila dan UUD 1945, bahwa aktivitas pemuda sebagai fasilitator pendamping desa adalah wujud pengabdian bela negara.

Demikian kesimpulan dari kajian makalah ini yang memabahas partisipasi pemuda sebagai fasilitator desa. Kurang dan lebihnya penulis memohon saran dan kritik yang membangun agar proses diskursus mengenai studi kepemudaan dapat berlanjut sebagai modal pengembangan khasanah ke ilmuan.
Pemuda sebagai fasilitator pendamping desa adalah Kader /regenerasi yang di memiliki desa untuk kemajuan dan keberlangsungan kehidupan desa; (4) Memper halus Bakat (skills) dengan pelatihan dan pendidikan; (5) Menjaga dan mengembangkan serta memahami sistem pengetahuan lokal, adat isitiadat yang berlaku di sautu desa; dan (6) Mengkomunikasikan kepentingan Nasional dengan mempertimbangkan hak masyarakat desa.

\section{DAFTAR PUSTAKA}

Abdullah, T. (1974). Pemuda dan Perubahan Sosial. Jakarta: $\mathrm{LP}_{3} \mathrm{ES}$.

Bens, V. (2012). Facilitating with ease! Core skills for facilitators, team leaders and members, managers, consultants, and trainers. San Francisco, California: Wiley.

Budi Utomo, M. C. R. (2005). Sejarah Indonesia Modern. Yogyakarta: Gadjah 
Journal of Millennial Community, 1 (2), September 2019

Syamsuddin

Mada University Press.

Holand,J. \& Black burn, J. (1998). Whose Voice? Participatory research and Policy change. London: Intermediate Technology Publication.

Ife.J dan Frank T. (2015). Altenatif Pengembangan Masyarakat di Era Globalisasi Community Development. Yogyakarta: Pustaka Pelajar.

Kartodrjdo, S. (1984). Komunikasi dan Kaderisasi dalam Pembangunan Pedesaan. Yogyakarta: ${ }_{3}$ PK UGM.

Mardikanto, T. (1994). Bunga Rampai Pembangunan Pertanian. Surakarta: Sebelas Maret University Press.

Nurcholis, H. (2011). Pertumbuhan $\mathcal{E}$ Penyelenggaran Pemerintahan Desa. Jakarta: Erlangga.

Peraturan Menteri Dalam Negeri Tentang Kependudukan. , Pub. L. No. Nomor 39 (2015).

R.Z. Leirissa dkk. (1989). Sejarah Pemikiran
Tentang Sumpah Pemuda. Jakarta: Departemen Pendidikan dan Kebudayaan.

Sastropoetro, S. (1986). Partisipasi, Komunikasi, Persuasi dan Disiplin dalam Pembangunan Nasional. Page | 44 Bandung: Penerbit Alumni.

Undang-Undang Tentang Desa., Pub. L. No. Nomor 6 (2014).

Undang-undang Tentang Kepemudaan. , Pub. L. No. Nomor 40 (2009).

\section{PROFIL SINGKAT}

Saya Syamsuddin lahir di kab. Berau Provensi Kalimantan Timur; pendidikan sarjana Si Pendiilan Luar Sekolah Universitas Mulawarman hingga menempuh pendidikan magister di bidang Pendidikan Non Formal kosentrasi Hubungan Masyarakat di Pasca Sarjana UNY lulus di tahun 2015 dan sekarang bekerja sebagai dosen tetap di universitas nahdlatul ulama kalimantan timur. 